\title{
POLITIZACIÓN DEL HABITAR EN LA CIUDAD DE BARCELONA: PRÁCTICAS COTIDIANAS MIGRANTES FRENTE AL COVID-19
}

Ulises Bernardino Márquez Pulido

Universitat Autónoma de Barcelona

\section{RESUMEN}

El presente artículo explora las "prácticas cotidianas" frente al covid-19 que realizaron las personas migrantes que viven en Barcelona durante los primeros meses posteriores a la declaración del estado de alarma y de la formulación del Real Decreto 463/2020 del Estado español. En principio presentamos el abordaje teórico-metodológico y realizamos un acercamiento estadístico de la población estudiada. Después estudiamos las "prácticas culturales" de la Red de Cuidados Antirracista que se formó para realizar ayudas y apoyo a las personas migrantes vulnerables que viven en Barcelona y hacemos un breve acercamiento a otras experiencias. Finalmente destacamos la importancia de la vida cotidiana en los procesos de organización social de los migrantes para enfrentar la pandemia y cómo se expresa en los usos y significaciones que se hacen de la ciudad y del espacio urbano configurando una politización del habitar.

Palabras clave: Prácticas cotidianas; Ciudad y espacio urbano; politización del habitar; Barcelona; Covid-19. 


\section{ABSTRACT}

This article examines the "everyday practices" of the immigrant population of Barcelona in relation to the Covid-19 context during the first few months after the Spanish government declared a State of Emergency (Real Decreto 463/2020, March 14). The first section sets out the theoretical and methodological approach followed along with statistical information about the study population. It then goes on to investigate the "cultural practices" of the Red de Cuidados Antirracista, a network set up to help and support vulnerable migrants who live in Barcelona, also offering a brief discussion of other cases. Finally, it emphasizes the special relevance of everyday life in the social organization processes activated by migrants to cope with the pandemic, in particular how everyday life is expressed within specific practices in the city and the urban space, configuring a particular politicization of habitation.

Keywords: Everyday practices; City and urban space; Politicization of habitation; Barcelona; Covid-19.

\section{INTRODUCCIÓN}

Desde hace décadas las ciudades son los centros neurálgicos de la organización social, económica, política y simbólica de las sociedades modernas, espacios donde se organiza el poder y se generaliza el "valor de cambio" (Lefebvre, 1973); lugares centrales de la "globalización" (Sassen, 1999) y el desarrollo de las tecnologías; sitios donde se configura la "mundialización de la cultura" (Ortiz, 2004). Al mismo tiempo las ciudades también son "estructuras de acogida" (Duch, 2002) de la "vida cotidiana", en las cuales se llevan a cabo las labores de transmisión pedagógica para que los seres humanos puedan por sí mismos realizar unas "praxis de dominación de la contingencia" (Duch, 2015); del mismo modo, las ciudades son los lugares propicios para la transformación social, la crítica política y el desarrollo de diferentes formas de relaciones sociales, espacios en los que se configura y potencia una "politización de las prácticas cotidianas" (De Certeau, 1996).

Con la irrupción del covid-19 en el mundo, las ciudades se han convertido en los principales centros de contagio de esta enfermedad y, por lo tanto, en espacios fundamentales para gestionar y superar la crisis sanitaria. Los Estados de todo el mundo llevan a cabo medidas para controlar los flujos y movimientos de personas en las grandes ciudades con el objetivo de disminuir los contagios y evitar el colapso de los sistemas sanitarios. En España las medidas de control sobre la población se aplican en todo el país, pero con énfasis en las principales ciudades como Madrid y Barcelona. 
Nuestra hipótesis es que la llegada y expansión del covid-19 ha provocado que los sectores sociales más vulnerables dentro de las ciudades (desempleados, migrantes, enfermos) se encuentren seriamente amenazados y que su situación de riesgo de exclusión social y de marginación económica crezca. En el caso español uno de estos sectores de la población es el de los inmigrantes y, sobre todo, los que se encuentran "sin papeles". Dada su condición "irregular" han tenido que enfrentar la pandemia en una situación jurídica, política y económica considerablemente adversa; su entorno de precariedad se profundizó aún más y sus posibilidades de subsistencia básica se vieron reducidas en extremo.

Si ya desde antes de la pandemia el espacio urbano de las ciudades, sus usos y significaciones, se encontraban en "disputa" (Harvey, 2013), con la amenaza provocada por el covid-19 y el aumento de la vulnerabilidad y la exclusión social esta situación se potencia y las contradicciones al interior de las ciudades aumentan, mientras en algunos países se pretende imponer un control radical de la población por parte de los Estados. En este contexto nos surgen las siguientes problemáticas: ¿qué acciones y "prácticas" han realizado los inmigrantes en Barcelona frente al covid-19?, ¿cuáles son algunas de sus organizaciones que han desplegado ayuda?, ¿el Estado español diseñó algún programa o política pública para este sector de la población?, ¿qué importancia tiene el espacio urbano de Barcelona en estos procesos socioculturales?

El presente trabajo tiene como objetivo dar a conocer algunas de las "prácticas cotidianas" de la Red de Cuidados Antirracista de Barcelona, que desplegó una serie de mecanismos para ayudar a las personas inmigrantes, llegando a apoyar con alimentos, medicinas, ropa, dinero, soporte psicológico, asesorías jurídicas, a más de ochocientas personas, entre marzo y julio de 2020. Asimismo, haremos referencias a otras experiencias similares, buscaremos dar a conocer sus "prácticas culturales" (Cassigoli, 2005) y sus estrategias políticas para enfrentar la crisis sanitaria y social profundizada por la pandemia. Al mismo tiempo expondremos la importancia del espacio urbano de Barcelona, su "producción", sus "usos" y "significaciones" que están en disputa y resaltaremos la importancia de la "vida cotidiana" en estos procesos, sociales e históricos.

\section{BASES TEÓRICO-METODOLÓGICAS}

Para comprender en profundidad la importancia de las "prácticas migrantes" en la ciudad de Barcelona partimos de los trabajos de Henri Lefebvre (1947, 1973), quien establece la importancia de la vida cotidiana y de la ciudad en el mundo moderno. Asimismo recuperamos su tesis de que en el espacio urbano de las ciudades se desarrollan y disputan las contradicciones entre "valor de uso" y "valor de cambio" y en este proceso la vida cotidiana juega un lugar central. También hacemos uso de los trabajos de Lluís Duch $(2000,2002,2015)$ sobre la ciudad como una "estructura de acogida" de la cotidianidad en la cual se despliega, entre otras dimensiones, el zoon politikón (Aristóteles, 2015) que es el anthropos. 
Por otra parte, recurrimos a los trabajos de Michel de Certeau (1996) sobre las "prácticas cotidianas": su recuperación de la filosofía marxista y su comprensión del mundo como "objeto de transformación" por medio de la "praxis" con base en una "interpretación" (una teoría); sus tesis kantianas de las "artes de hacer" cotidianas como una "ética" y una "estética"; la influencia de Freud en dos grandes niveles, primero destacando que no hay separación entre "psicología individual" y "psicología social” y segundo el "retorno de lo reprimido" en la vida de la ciudad; finalmente, en contrasentido a las tesis de Foucault y la "vigilancia generalizada" por medio del panóptico, De Certeau propone la existencia de "prácticas microbianas" que se insertan en los mecanismos del poder tecnócrata alterando su funcionamiento ${ }^{1}$.

De modo que para este trabajo, la "vida cotidiana" es la "realidad radical" en la que, desde el nacimiento hasta la muerte, individuos y comunidades se forman y transforman en el transcurso de las historias culturales y las biografías individuales, a través de un permanente "trayecto hermenéutico, logomítico" (Duch, 1998), en el que la "interpretación” y "construcción" de la realidad y la "imagen del ser humano" (Rombach, 2004) tienen una relación indisociable. La ciudad es una "estructura de acogida" de la cotidianidad y en la actualidad es uno de los centros principales de la organización social, donde se manifiestan ejemplarmente sus contradicciones y sus posibilidades futuras.

Para nosotros, las "prácticas cotidianas" de los migrantes en Barcelona frente al covid-19 se despliegan en el contexto de una urbe capitalista y operan como un contrasentido a las lógicas hegemónicas de la economía; representan una "politización del habitar" (Cassigoli, 2016) la ciudad y los espacios urbanos que se opone a la lógica del "valor de cambio"; pertenecen a los "márgenes" de la sociedad dominante con un impacto directo en la "vida cotidiana" de la ciudad y una alteración en sus formas; manifiestan la dimensión cordial de "acogida" que se auto-proporcionan los habitantes inmigrantes de Barcelona.

Para dar respuestas a nuestras preguntas de investigación — ¿cuáles son algunas "prácticas cotidianas" de los migrantes en Barcelona frente al covid-19?, ¿cuáles son algunas de las organizaciones que realizaron acciones de ayuda y qué papel jugó el Estado español en estos procesos? - proponemos una metodología que consistió en la combinación estratégica de técnicas de observación y recolección de datos; definimos un "sujeto" de estudio, la Red de Cuidados Antirracista, y delimitamos temporalmente nuestra investigación al periodo en el que estuvo vigente el Real Decreto 463/2020, del 14 de marzo al 21 de junio de 2020.

1. Para una profundización, véase directamente Michel de Certeau (1996); para una comprensión de las "fuentes" primarias de su obra, véase Rossana Cassigoli (2016).

2. Para una profundización sobre el estudio de la vida cotidiana en las Ciencias Sociales y Humanidades, véase Márquez (2017). 
Nos ayudamos de las estadísticas proporcionadas por el Instituto de Estadística de España, por el Departament d'Estadística i Difusió de Dades de Cataluña, por las investigaciones de Ismael Gálvez (2020) y por las cifras que calcula el movimiento social migrante \#RegularizaciónYa. Realizamos un análisis e interpretación de la producción de vídeos, audios, entrevistas, comunicados y publicaciones que la Red de Cuidados Antirracistas realizó durante los meses de estudio y que publicó a través de sus redes sociales. Desde nuestra perspectiva (Nietzsche, 2005), la exposición del problema y los intentos de resolución por los propios actores involucrados, es nuestro principal "material" de investigación de las "prácticas cotidianas" de los inmigrantes, así que su producción audiovisual y escrita es la principal fuente de análisis e interpretación.

Finalmente, elaboramos un cuestionario dirigido a migrantes de África, Asia y América Latina que viven en Barcelona, que participaron o participan en colectivos y que realizaron y realizan acciones de ayuda y apoyo mutuo para enfrentar la crisis producida por la pandemia (Márquez, 2020). Este llevó por título: Guía de observación para explorar las "prácticas cotidianas" de las personas migrantes ante el COVID-19 en Barcelona, y constó de diecinueve preguntas en torno a tópicos como su experiencia del covid-19, los cambios en su "vida cotidiana" o las actividades para enfrentar la pandemia. Lo socializamos a través de las redes sociales y recibimos diecisiete respuestas.

\section{MIGRACIÓN EN ESPAÑA ANTES DEL COVID-19}

De acuerdo con el Instituto Nacional de Estadística de España ${ }^{3}$, comenzando el año 2020 había una población de 47.329.981 residentes en el territorio español, de los cuales 5.235.375 eran extranjeros, que representan un $11 \%$ de la población total. Según las investigaciones de Ismael Gálvez (2020)4, de la Universidad Carlos III de Madrid, a finales del año 2019 el número de inmigrantes que residían de manera "irregular" en España era de entre 390.000 y 470.000 personas, lo que representa entre un 7,4\% y un $8,9 \%$ del total de extranjeros. Según sus propias estimaciones, el 77\% de esta población es de Sudamérica y Centro América (sin contar México); el 9,2\% proviene de África, el 13,8\% restante se reparte entre europeos no comunitarios, Norte América (México, Estados Unidos y Canadá), Asia y Oceanía.

De manera autónoma, los integrantes del movimiento \#RegularizaciónYa ${ }^{5}$, conformado por cerca de mil quinientos colectivos y organizaciones sociales de toda España, calcula que hay más de 600.000 inmigrantes en situación "irregular", lo que representaría un 11,4\%

3. Disponible en https://www.ine.es/

4. Dado que no existen datos oficiales, este investigador ha realizado un esfuerzo por tratar de dimensionar el número de personas "sin papeles" que residen en España. Recientemente publicó sus resultados en los archivos de la Universidad Carlos III.

5. Disponible en https://regularizacionya.com/descargaycomparte/ 
de la población extranjera en España. Estos datos los obtienen cruzando información de estadísticas oficiales, como el Padrón Municipal, y los datos sobre extranjeros con permiso de residencia arrojados por el Observatorio Permanente de la Inmigración.

En el caso de la comunidad de Cataluña, según cifras del Departament d'Estadística i Difusió de Dades ${ }^{6}$, a principios del año 2020 se registra una población de 7.727 .029 habitantes que representa un $16 \%$ de la población española, mientras que en Barcelona residen 1.666.530 personas, un 3,5\% de habitantes del territorio español. Dentro de Barcelona viven 228.633 inmigrantes no europeos (24.601 africanos, 116.577 latinoamericanos y 86.843 asiáticos), un $13,7 \%$ de la población total de la ciudad.

Dado que no existen datos sobre el número aproximado de personas "sin papeles" que residen en Barcelona, proponemos una homologación de los porcentajes generales de España para, al menos, tener una idea aproximada de las cifras y dar cuerpo a los números. Si homologamos los datos de Gálvez (2020), tendríamos que, de los 228.633 residentes inmigrantes, entre un 7,4\% y un 8,9\% se encuentran en situación "irregular", es decir, entre 16.918 y 20.348 personas. Si consideramos los datos del movimiento \#RegularizaciónYa, la cifra se eleva hasta 26.064 personas, que representarían un 11,4\% de los inmigrantes.

Debido a la Ley de Extranjería del Estado español, los inmigrantes "sin papeles" no tienen derecho a contrato laboral, por lo tanto, la mayoría no tiene ingresos económicos estables, ni acceso al sistema de salud público. Además, algunos tienen trabajos precarios y de baja remuneración, y un gran número se dedica a tareas del hogar y del campo. Tampoco tienen derecho a la educación pública. Asimismo, no pueden acceder a ningún tipo de programa social del Estado. Si son detenidos por alguna institución policial, pueden ser llevados a los Centros de Internamiento para Extranjeros y deportados. Básicamente no se les considera "sujetos de derecho".

Es en medio de este contexto social que el covid-19 irrumpe y comienza su rápida expansión. En diciembre de 2019 la provincia china de Wuhan registró los primeros contagios en el mundo. Un mes después, el 30 de enero de 2020, la Organización Mundial de la Salud (OMS) declara una "emergencia sanitaria de nivel internacional". Para ese momento había presencia registrada del virus en al menos quince países más. El 11 de marzo de 2020 la enfermedad estaba expandida en más de cien países. La OMS declaró la "pandemia internacional" y pocos días después, el 14 de marzo de 2020, el Estado español dictó el "Real Decreto 463/2020 por el que se declara el estado de alarma para la gestión de la situación de crisis sanitaria ocasionada por el Covid-19", vigente hasta el día 21 de junio.

6. Disponible en https://www.bcn.cat/estadistica/castella/index.htm. 


\section{COVID-19 Y PRÁCTICAS COTIDIANAS MIGRANTES: LA RED DE CUIDADOS ANTIRRACISTA}

Una de las primeras lecciones que nos recuerda la expansión del covid-19 es que la vida humana se encuentra en una permanente "contingencia" (Duch, 2002) y que irremediable nos amenaza la muerte por el hecho mismo de vivir en el mundo. Al mismo tiempo, también nos recuerda que la "amenaza" a la vida provocada por la pandemia es desigual en las sociedades marcadas por las diferencias entre clases y grupos sociales en donde el acceso a vivienda, el trabajo y la salud es altamente diferenciado. En el caso de España, los inmigrantes "sin papeles" se encuentran entre los grupos más vulnerables y marginados de la sociedad, como antes mencionamos, prácticamente no son considerados "sujetos de derecho" y esta situación es crítica para su supervivencia, para mantener su salud física y psicológica y para enfrentar la amenaza del coronavirus.

En Barcelona, como calculamos atrás, es posible que vivan más de veinte mil personas "sin papeles". Sin duda, la llegada del covid-19 los colocó en situaciones de mayor peligro y vulnerabilidad. Así lo reflexiona Naty Messias, una de las impulsoras de la Red de Cuidados Antirracistas, en una entrevista con TV3 el 1 de abril de 2020:

"Un grupo de personas que militamos en diferentes colectivas [sic] antirracistas pensamos que si nosotres [sic] lo íbamos a pasar mal, habría mucha más gente que la pasaría peor que nosotres [sic], entonces decidimos hacer, pues, lo que estuviera en nuestra mano para que a nadie le faltara lo más básico" (Messias, 2020).

Algunas de las personas que respondieron nuestro cuestionario, cuando se les preguntó por los cambios en su vida cotidiana a partir de la llegada del covid-19, escriben lo siguiente. Laura": "Trabajar con hijos pequeños fue muy duro [...], no podía dejar de trabajar y descuidé mucho el cuidado de mis hijos". Marta, otra migrante que nos ayudó respondiendo el cuestionario, describe lo siguiente:

"Al pasar tiempo completo en el piso con compañeros de casa, además del estrés propio de la situación, se generaron roces y conflictos... Comencé a sentir rechazo a salir, y me busqué estabilizar emocionalmente por medio de mis aficiones (música y literatura)".

Otra de nuestras entrevistadas, Julia, responde: "Quedé desempleada y sin protección del Estado, además de problemas de ansiedad y salud mental por mi situación económica". Finalmente, María escribe: "Sin trabajo profesional, he tenido que hacerme cargo de la crianza y trabajos del hogar más que antes".

7. Los nombres son ficticios.

8. Todos los testimonios del cuestionario son de septiembre de 2020. 
Es en este contexto que distintos individuos y colectivos comienzan a organizarse y a formar grupos de solidaridad y apoyo para proporcionar ayuda a las personas y comunidades de inmigrantes que más lo necesitaran. Por ejemplo, menciona Naty Messias (2020):

"[Se trata de personas] que no tienen acceso a las ayudas del ayuntamiento o a ninguna ayuda social, como pueden ser el colectivo de trabajadoras sexuales, el colectivo de personas que se dedican a la recolección de chatarra, el colectivo de compañeras trans y travestis; algunas personas también que tienen dificultades de salud que no les permite salir a la calle y son personas que normalmente suelen vivir al día, con lo que no se pueden permitir comprarse a la mejor cien euros de golpe de comida o no se pueden permitir salir a la calle para comprar la comida”.

Así, en medio de un marco jurídico adverso y una situación de riesgo sanitario profundizado por el covid-19, personas y grupos se organizaron para formar la Red de Cuidados Antirracista que quedó integrada por los siguientes colectivos: Can Migra, La Nova Usurpada, T.I.C.T.A.C, Disidencias Sexogenéricas Antirracistas, Tejiendo Redes, Maricas Libertarias, Sabor Pacífico, Tres Guiris y El Banco Expropiado. Su objetivo principal era colaborar en conjunto para proporcionar ayuda alimentaria, medicina y soporte emocional a todas las personas migrantes que pudieran llegar y que lo necesitaran.

La Red comenzó a dar a conocer sus objetivos y a solicitar colaboraciones por medio de las redes sociales: crearon un perfil en Facebook, un canal de Telegram, un blog y un correo electrónico ${ }^{9}$. A través de estos medios dan difusión a sus acciones y convocan a nuevos colectivos y personas a participar en dar y recibir ayuda. Parte de esta investigación se basa en la documentación, análisis e interpretación de sus propias producciones y praxis que socializan por medio de estos canales.

Cuatro días después de lanzado el Real Decreto 463/2020, el 18 de marzo, la Red de Cuidados publica uno de sus primeros comunicados. Reproducimos unos extractos:

"En vista del decreto de Alerta Sanitaria dictado por el Estado Español a raíz del Covid-19 o coronavirus y su impacto en la comunidad, diversos colectivos y personas vinculadas al movimiento migrante y antirracista apelamos a vuestra ayuda material para poder cubrir las necesidades de compañeres [sic] de nuestras comunidades que están en situación de extrema vulnerabilidad [...]. Creemos que esta coyuntura debe ser una oportunidad para poner en valor los cuidados colectivos y la necesidad de fortalecer la interdependencia como respuesta y resistencia a los procesos de salud-enfermedad individualistas y capitalistas [...]. En tal sentido ponemos en funcionamiento una red de apoyo mutuo de diferentes colectivas

9. Los perfiles públicos son los siguientes: Facebook: https://www.facebook.com/redcuidadosbarcelona/. Canal de Telegram: https://t.me/redcuidados Blog: redantirracistacuidados.wordpress.com. Correo electrónico: redantirracistacuidados@gmail.com. 
[sic] del tejido asociativo de Barcelona, de comunidades migrantes racializadas y sexogénerodisidentes y aliadas" (Solidaridad y dignidad, procesos comunitarios de sostén de la vida, 2020, 18 de marzo).

Además, denuncian la inexistencia de políticas públicas por parte del Estado español que atiendan a los sectores sociales más vulnerables y en riesgo de exclusión social. Dos semanas después despliegan una de sus primeras "rutas de cuidado alimentario" que parte del barrio de Gracia y pasa por sitios como La Sagrada Familia, Guinardó, Nou Barrris, Sant Andreu, y fuera de Barcelona, por Moncada y Reixach:

"Aproximadamente a las $19 \mathrm{~h}$, les llevaremos a sus casas comida a quienes por razones de papeles, salud, maternidad, entre otras, no pueden salir. Es un hermoso e inmenso esfuerzo de muches [sic] para que esta labor sea realidad" (Solidaridad y dignidad, 2020, 30 de marzo).

La urgencia y la gravedad de la situación demandaba una pronta respuesta para ayudar a los grupos sociales más vulnerables. Menos de un mes después del Decreto 463/2020, el 9 de abril, la Red de Cuidados ya tenía cinco "rutas de cuidado alimentario" y el 17 de abril, un mes después del Decreto, tenían seis rutas. Su distribución se daba principalmente por los siguientes barrios: El Gótico, El Born, Gracia, Sants, Sant Andreu, Vall d’Hebron, y fuera de Barcelona en Hospitalet de Llobregat, Moncada y Reixach. La ayuda alcanzaba a más de ciento cincuenta personas.

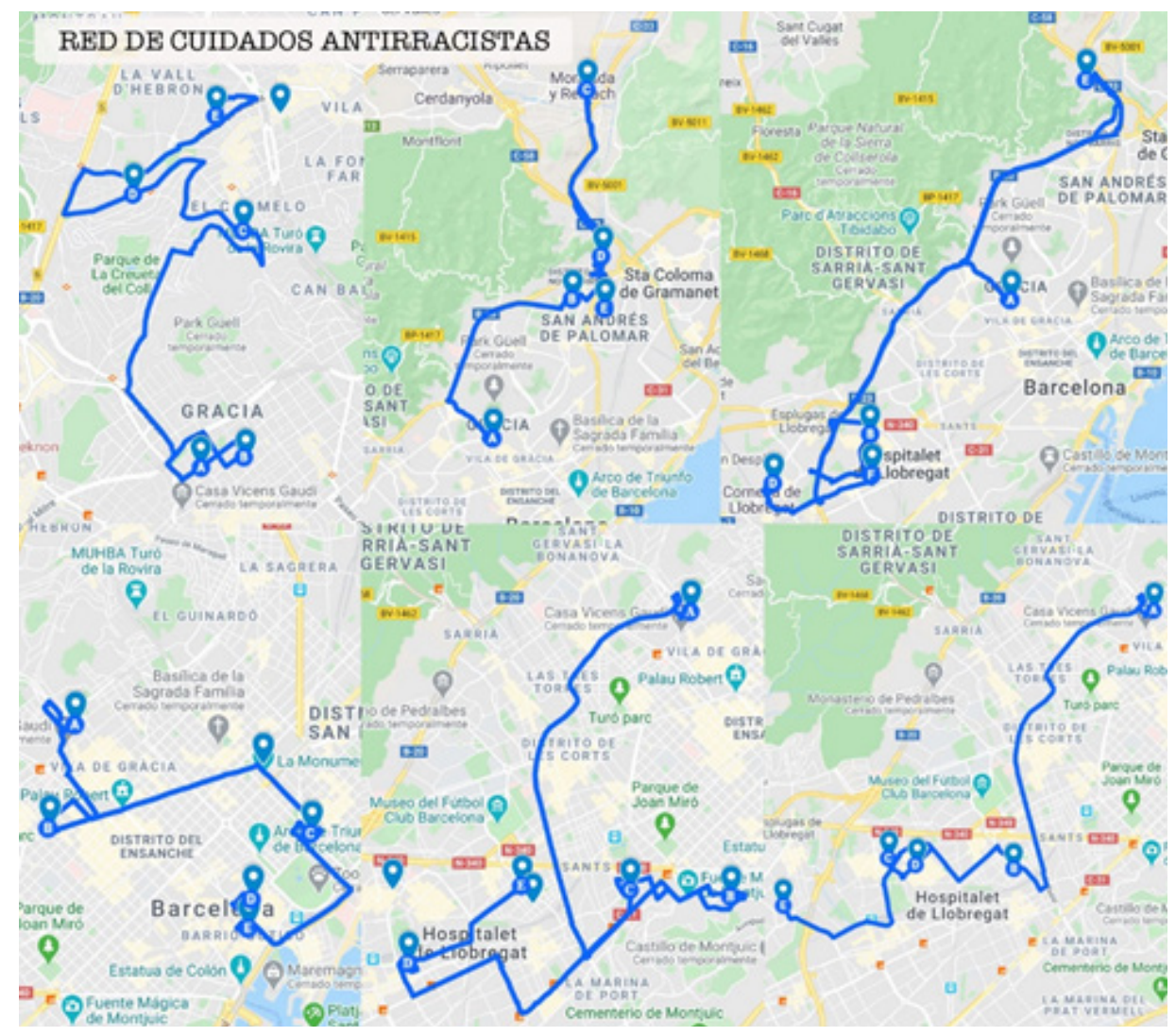

Imagen 1. Seis rutas de cuidado alimentario. Fuente: Red de Cuidados Antirracista. 
Los primeros espacios de la ciudad en los que se estaban llevando a cabo la recolección de alimentos y otras ayudas eran Casal 3 Liris (en Gracia) y la Librería Prole (en Sant Antoni). Estos dos espacios funcionaron durante gran parte del periodo de emergencia. Posteriormente, en el transcurso de las siguientes semanas, se fueron sumando otros. El día 15 de junio participaban nueve lugares como centros de acopio de alimentos, ropa, medicina, etc. ${ }^{10}$

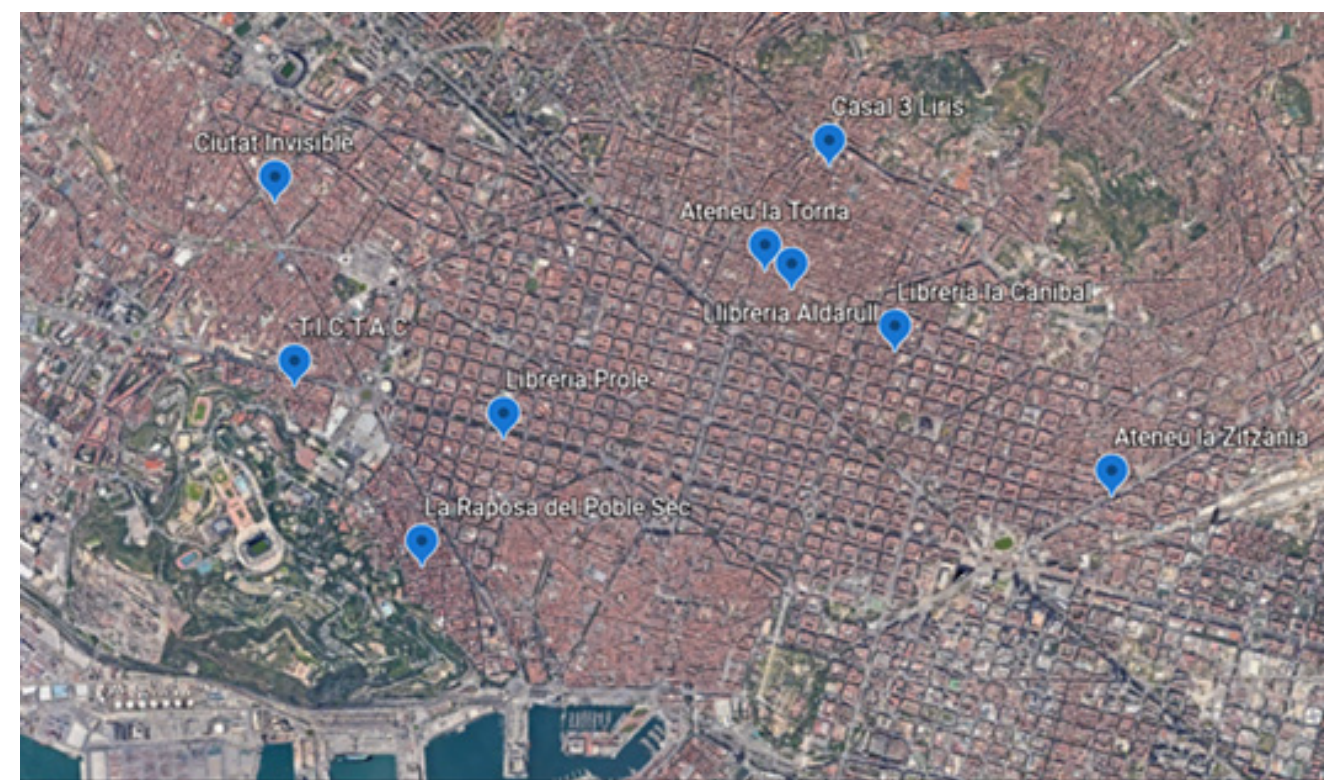

Imagen 2: Centros de acopio de la Red de Cuidados Antirracista de Barcelona. Fuente: elaboración propia.

Es destacable observar cómo las "prácticas cotidianas" migrantes se espacializan (Lefebvre, 2013) por medio de los usos, significaciones y discursos que se hacen de la ciudad. Asimismo, es importante mencionar que se despliegan en medio de un contexto adverso desarrollándose a contracorriente de un Decreto que prohíbe la circulación y el movimiento de personas, situación que afectó directamente las labores humanitarias en variadas ocasiones. Por ejemplo, el día 30 de marzo, durante una de las primeras rutas para llevar comida, dos integrantes de la Red fueron detenidos por la Guardia Urbana de Barcelona. Los voluntarios contaban con el impreso del "Certificado de autorresponsabilidad de desplazamiento de la Generalitat"

10. Además de los dos espacios mencionados atrás, se adhirieron los siguientes: Librería la caníbal (La Dreta de L'Eixample), Ciutat Invisible (Sants), Ateneu la Torna (Gracia), Llibreria Aldarull (Gracia), Ateneu la Zitzània (el Clot), La Raposa de Poble Sec (Poble Sec) y T.I.C.T.A.C. (Poble Sec).

11. Este certificado fue un documento creado por la Generalitat para que las personas que necesitaran desplazarse fuera de sus domicilios por cuestiones urgentes lo pudieran hacer sin ser denunciados. 
Aun así, fueron demandados por infracción del artículo 36.6 de la Ley de Seguridad Ciudadana que les hacía acreedores de multas de entre 300 y 30.000 euros. Una semana y media después, el 9 de abril, otro integrante de la Red es multado nuevamente por los mismos motivos $^{12}$.

Estas detenciones no son aisladas; en otras partes del Estado español sucedían situaciones similares. Por ejemplo, el 23 de junio las organizaciones SOS Racismo y Fruita amb Justicia Social denuncian conjuntamente que durante la vigencia del Real Decreto 463/2020 aumentaron las "redadas racistas", que consisten en la detención e identificación de las personas con un perfil "racializado", especialmente de los trabajadores del campo:

"Denunciamos que las administraciones en vez de ser garantes de los derechos de toda la ciudadanía y de dar una solución digna a centenares de personas en situación de extrema vulnerabilidad, utilizan los cuerpos de seguridad pública para acosarlas con dispositivos de control, expulsión y criminalización que generan más hostilidad a la población y que normalizan entre los vecinos que las personas racializadas sean objeto de acoso policial, aunque no estén cometiendo ningún delito" (El racisme institucional castiga i criminalitza els temporers de Lleida amb controls policials, 2020, 23 de junio ${ }^{13}$.

De modo que el Estado no solo no había diseñado ningún tipo de política pública para atender las necesidades básicas de los inmigrantes "sin papeles" afectados gravemente por la pandemia, sino que, además, las autoridades policíacas obstaculizaban las labores humanitarias de organizaciones como la Red de Cuidados, impidiendo que llegara la ayuda alimentaria a personas necesitadas de ella y aumentando las "redadas racistas". El control sobre el espacio urbano de la ciudad, sus usos y prácticas están en disputa entre dos formas de enfrentar la crisis sanitaria provocada por el covid-19: la de las instituciones del Estado y la de los migrantes "sin papeles".

En este contexto se formó dentro de la Red de Cuidados una Red Jurídica Antirracista que se puso en contacto con el ayuntamiento de Barcelona para explicar los casos de las personas multadas y solicitar que retiraran las multas. Según su propia versión, el ayuntamiento les respondió que el "Certificado de autorresponsabilidad" no era válido para llevar a cabo labores humanitarias y que necesitaban un documento emitido por SOS Racismo para poder seguir con sus actividades. La Red Jurídica se puso en contacto con dicha organización y le fueron otorgados los documentos que solicitaba el ayuntamiento. A pesar de ello, la Guardia Urbana continuó multando a los voluntarios. La Red emitió un comunicado el 12 de abril:

12. Las detenciones y multas a los integrantes de la Red fueron documentas por diferentes medios de comunicación, como, por ejemplo, el periódico El Público de Madrid (15 de abril), El Salto Diario (9 de abril) o Directa, diario catalán (2 de abril).

13. Traducción propia. 
"Es sumamente contradictorio e incomprensible que el Ayuntamiento de Barcelona declare públicamente que no dará curso a las sanciones, que luego solicite a SOS Racismo que nos emita una certificación "válida", ya que el certificado de la Generalitat "no sirve", y que luego de obtener las nuevas certificaciones, su policía, la Guardia Urbana, nos siga multando, poniendo en duda la veracidad de nuestra labor y tratando[nos] con prepotencia" (Comunicado por las multas contra integrantes de la Red de Cuidados Antirracista, 12 de abril de 2020).

El covid-19 seguía expandiéndose por la ciudad y el peligro de contagio crecía mientras el acoso policial contra migrantes "racializados" aumentaba, lo cual no impidió que la Red de Cuidados siguiera creciendo y desarrollando sus "prácticas culturales" (Cassigoli, 2005) de solidaridad y apoyo incondicional para con las personas más vulnerables y desatendidas por las instituciones: la mayoría inmigrantes "sin papeles", sin trabajo y sin derecho a paro: recolectores de chatarra, trabajadoras sexuales, transexuales, trasvestis, madres solteras, personas enfermas y con problemas de movilidad.

El Estado únicamente se preocupó por la macroeconomía y por mantener el control político. Por ejemplo, el día 7 de abril de 2020 se aprobó el "Real Decreto-ley 13/2020, por el que se adoptan determinadas medidas urgentes en materia de empleo agrario". En principio este decreto mencionaba que debido a la pandemia provocada por el covid-19 la producción agrícola en España estaba en riesgo de perderse, la cadena alimentaria podía detenerse y provocar desabastecimiento de mercancías y el aumento de los precios de los productos básicos. La causa es que no se contaba con la mano de obra suficiente debido a que miles de migrantes, que se emplean cada año en el campo, no habían llegado a trabajar por causa del coronavirus.

El decreto reconoce la importancia y la necesidad de los trabajadores inmigrantes para el funcionamiento adecuado de la economía española y acepta, sobre todo implícitamente, que su participación resulta fundamental para amortiguar la crisis y evitar un colapso mayor. Las medidas legales incluían la posibilidad de trabajar a las personas en desempleo o en cese de actividad, a los trabajadores cuyos contratos se hubieran visto temporalmente suspendidos, a las personas inmigrantes cuya Tarjeta de Identidad de Extranjero con permiso de residencia y trabajo caducara entre la entrada en vigor de ese Real Decreto y el 30 de junio de 2020, y a los jóvenes ex tutelados de entre 18 y 21 años con permiso de residencia en vigor. En todo caso, solo podían beneficiarse las personas cuyo domicilio se encontrara cerca del lugar de trabajo, no permitiéndose ningún tipo de desplazamiento. Como atrás mencionamos, este último decreto establece políticas públicas que no toman en cuenta a las personas migrantes "sin papeles", sino solo a las que ya cuentan con los permisos legales para trabajar. Además, no considera que, dado el riesgo de colapso de la producción agrícola y la exposición a un mayor riesgo de contagio de covid-19, estos trabajadores deberían tener ingresos más altos y contar con medidas de protección y 
seguridad que garanticen su integridad física y emocional. Como menciona la Red de Cuidados Antirracista,

"se trata de una medida utilitarista, provocada por la paralización del contingente temporal en las campañas agrícolas de algunas CCAA (como Andalucía y Catalunya [sic] entre otras) y el déficit de los 300 mil trabajadorxs temporerxs [sic] que llegan cada año al estado español. Se pretende evitar el desabastecimiento alimentario y el alza de precios en plena pandemia a costa de fuerza de trabajo de las personas migradas sin garantizar condiciones mínimas, reales y adecuadas de trabajo" (Comunicado en relación a la aprobación del real decreto-ley 13/2020, de 7 de abril, 2020, 9 de abril).

Si ya antes del covid-19 las condiciones de trabajo de muchos migrantes que se ganan la vida en el campo español eran paupérrimas, con la aparición del virus la situación se vuelve aún más arriasgada y ni el Estado ni las empresas aplican medidas para proteger la vida de los trabajadores; al contrario, hay una desatención, olvido y menosprecio. Por ejemplo, a finales de julio de 2020 un jornalero que trabajaba en Murcia en una plantación de sandías fue abandonado por los empleadores a las afueras de un centro de salud y poco después murió de deshidratación. Según testimonios de sus compañeros, la víctima, igual que todos ellos, era sometida a jornadas de trabajo de once horas diarias, desde las cinco de la mañana, sin que se le proporcionara agua o comida durante mucho tiempo ${ }^{14}$.

Como podemos observar, las instituciones, las empresas y las llamadas fuerzas del orden y seguridad del Estado tienen rasgos racistas, producen la discriminación de personas racializadas, niegan la ayuda a quienes están en situación “irregular", pero también a algunos que residen "legalmente". Estas son algunas de sus formas de gestionar la pandemia. Por este contexto, desde principio de abril de 2020, diferentes organizaciones sociales y colectivos lanzaron una campaña a nivel nacional para exigir la inmediata "regularización" de las personas "sin papeles" que residen en España desde antes de la pandemia y exigir el cierre de los Centros de Internamiento para Extranjeros.

La iniciativa se agrupó en un movimiento autodenominado \#RegularizaciónYa, entre los que se incluía la Red de Cuidados Antirracista, e inició una campaña en las redes sociales el 12 de abril, a menos de un mes después del inicio del estado de alarma. A partir de este momento y en el transcurso de los siguientes meses, redactaron una Proposición No de Ley (PNL) para lograr que el Congreso español aceptara la regularización inmediata de todas las personas que lo solicitaran, consiguiendo el apoyo de la Coordinadora Obrim Fronteras y de algunos grupos parlamentarios (Esquerra Republicana de Catalunya,

14. La noticia fue documentada por diferentes diarios, por ejemplo, El País (3 de agosto): https:// elpais.com/espana/2020-08-03/la-muerte-de-un-temporero-en-murcia-jornadas-de-11-horas-amas-de-40-grados-y-sin-agua.html, y La Vanguardia (1 de agosto): https://www.lavanguardia.com/ sucesos/20200801/482627897146/murcia-lorca-golpe-de-calor-temporero-jornalero-sutunella.html. 
CUP, Euskal Herria Bildu, Unidas Podemos, Grupo Parlamentario Plural). El 16 de junio se registró en el Congreso de los Diputados:

"El movimiento \#RegularizaciónYa y la Coordinadora Obrim Fronteras, apoyadas por más de 1500 asociaciones, organizaciones, colectivos y personas migrantes y antirracistas del Estado español, hemos registrado en el Congreso este viernes una PNL que insta al gobierno a iniciar un proceso de regularización para las más de 600.000 personas migrantes en situación irregular que residen en el Estado español. [...] Se plantea esta iniciativa bajo el actual panorama extraordinario por una cuestión de justicia social y de equiparación de derechos de todas las personas, instando también a repensar un cambio de paradigma, donde la vida de todas las personas esté en el centro" (Comunicado registro de Proposición No de Ley en el Congreso, 2020, 19 de junio).

El espacio urbano de las ciudades fue utilizado nuevamente como sitio de las reivindicaciones. En distintas urbes de España los inmigrantes salieron a exigir la aprobación de esta iniciativa. En Barcelona, diferentes colectivos y organizaciones, como el Sindicato Popular de Vendedores Ambulantes y la propia Red de Cuidados Antirracista, convocaron a una concentración en la Plaza Sant Jaume el día 19 de julio, a la cual acudieron alrededor de cien personas.

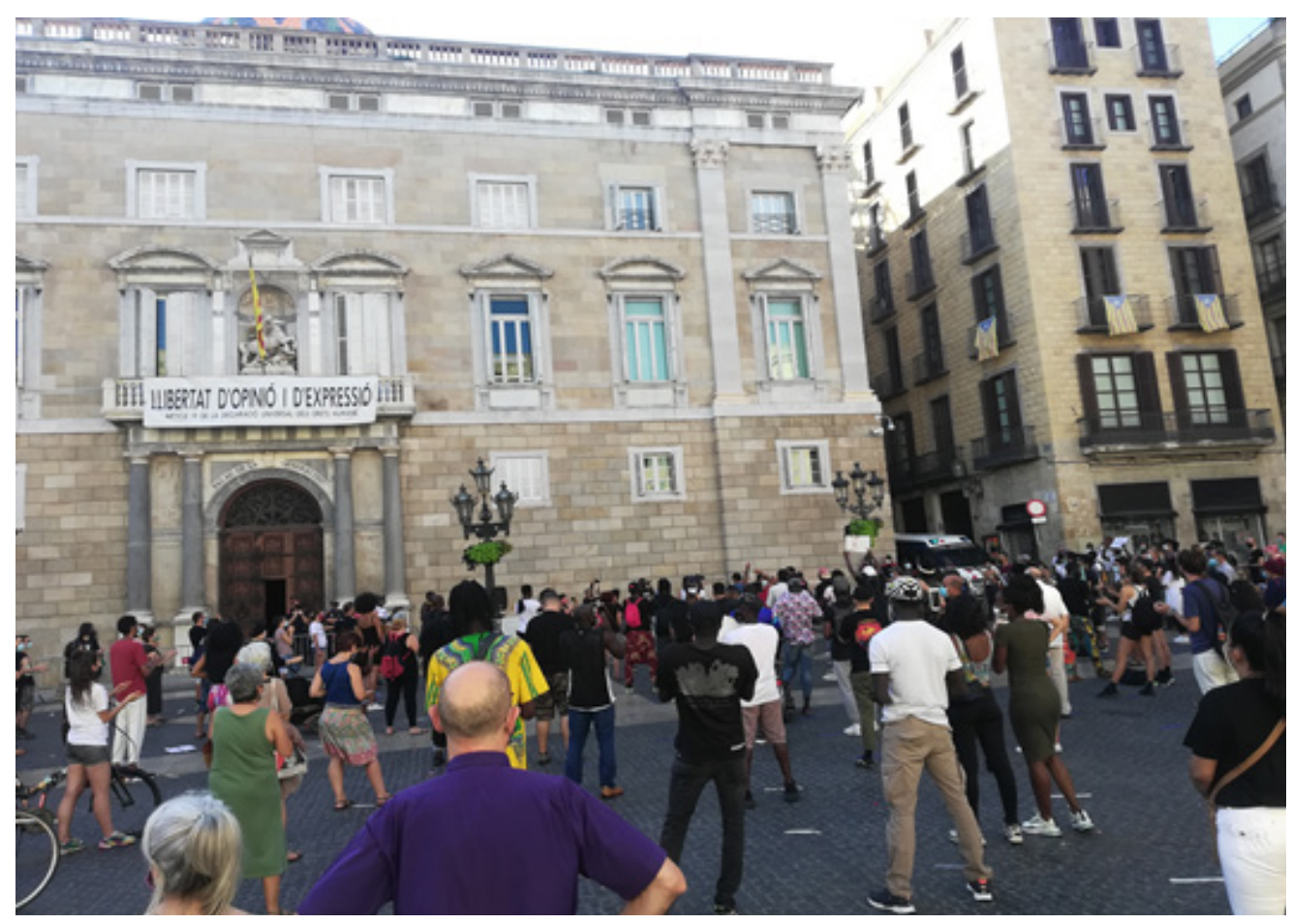

Imagen 3: Concentración política de inmigrantes por la regularización de las personas sin papeles, Plaza Sant Jaume, 19 de julio de 2020. Fuente: elaboración propia. 
Después de unos meses de discusiones, la PNL fue presentada al Congreso español el 22 de septiembre por el grupo parlamentario de Esquerra Republicana de Catalunya. La propuesta fue rechazada con 278 votos en contra (PSOE, PP, PNV, VOX y Ciudadanos), 59 a favor y 8 abstenciones. Además, cerraron la puerta a una futura discusión argumentando que la "normativa europea" no permite "regularizaciones exprés". Sin embargo, y como mencionan los propios integrantes de \#RegularizaciónYa, la "normativa europea" no se opone a este tipo de iniciativas, pues en Portugal, a inicios de la pandemia, se regularizó masivamente a miles de migrantes que estaban "sin papeles"15.

A pesar de este panorama desolador, la Red de Cuidados Antirracista siguió creciendo y desplegando sus recursos para llegar a todas las personas que pudieran. Si en el primer mes después del Decreto 463/2020, asistían a más de 150 personas, en los siguientes meses esta cifra se multiplicó. El 15 de junio reportan:

"Estamos en perspectiva de llegar a 800 personas en unas semanas. Nuestra idea es poder optimizar nuestras energías y poder extender unos meses más la cobertura de alimentos a nuestras comunidades fuertemente golpeadas por la crisis económica y social desatada. [...] Hemos sido cerca de 100 personas colaborando intermitentemente, un enjambre a veces caótico, un tejido ancestral. Una familia. Ha sido un esfuerzo tremendo no exento de dificultades, agobios y deplorables multas. Lo hemos hecho a pulso entre todes [sic]. Poniendo la vida al centro" (Tres meses de actividad, 2020, 15 de junio).

Un mes y medio después, la Red de Cuidados finalmente realizó las últimas recogidas de ayuda y rutas de apoyo alimentario. Para ese momento estaban llegando a más de 800 personas y 300 familias, con la colaboración de más de 100 personas y una docena de vehículos. No cabe duda de que todas sus acciones atenuaron significativamente la amenaza de muerte provocada por el covid-19 a los migrantes "sin papales" y a las personas racializadas que viven en Barcelona. Gracias a ellas seguramente se salvaron decenas de vidas, se evitó una mayor propagación de la enfermedad y se aminoraron los riesgos y angustias de cientos de personas.

\subsection{Otras experiencias migrantes y algunas "prácticas microbianas"}

Junto a la Red de Cuidados Antirracista, existen otras prácticas organizadas de migrantes, como las del Sindicat de la Imatge (UPIFC). Según Paulina, una de sus integrantes, que respondió nuestro cuestionario, esta organización "creó una sección sindical para agrupar el material que se había creado durante el periodo de alarma y crear un fondo documental. La idea es vender estas imágenes para ayudar a los afiliados y afiliadas del sindicato." Algunos de ellos son migrantes.

15. En este enlace se puede consultar la respuesta del movimiento \#RegularizaciónYa ante la negativa del Congreso: https://regularizacionya.com/comunicado-de-respuesta-ante-el-rechazo-de-la-pnl/. 
Otro ejemplo es el Sindicato Popular de Vendedores Ambulantes, compuesto principalmente por personas afrodescendientes, que crearon un banco de alimentos para autoabastecer a por lo menos 300 de sus integrantes. Asimismo, transformaron su tienda en un taller de costura para producir mascarillas y batas sanitarias para ayudar a cubrir el desabastecimiento que sufrieron farmacias, centros de salud y hospitales ${ }^{16}$. Además de estas experiencias, en todo el territorio de España se crearon cientos de grupos y colectivos para enfrentar la pandemia al margen de las acciones que estaba realizando el Estado. En un esfuerzo por darse a conocer, todas estas agrupaciones crearon un mapa en el que se localizan casi 500 iniciativas sociales que se desplegaron por toda España:

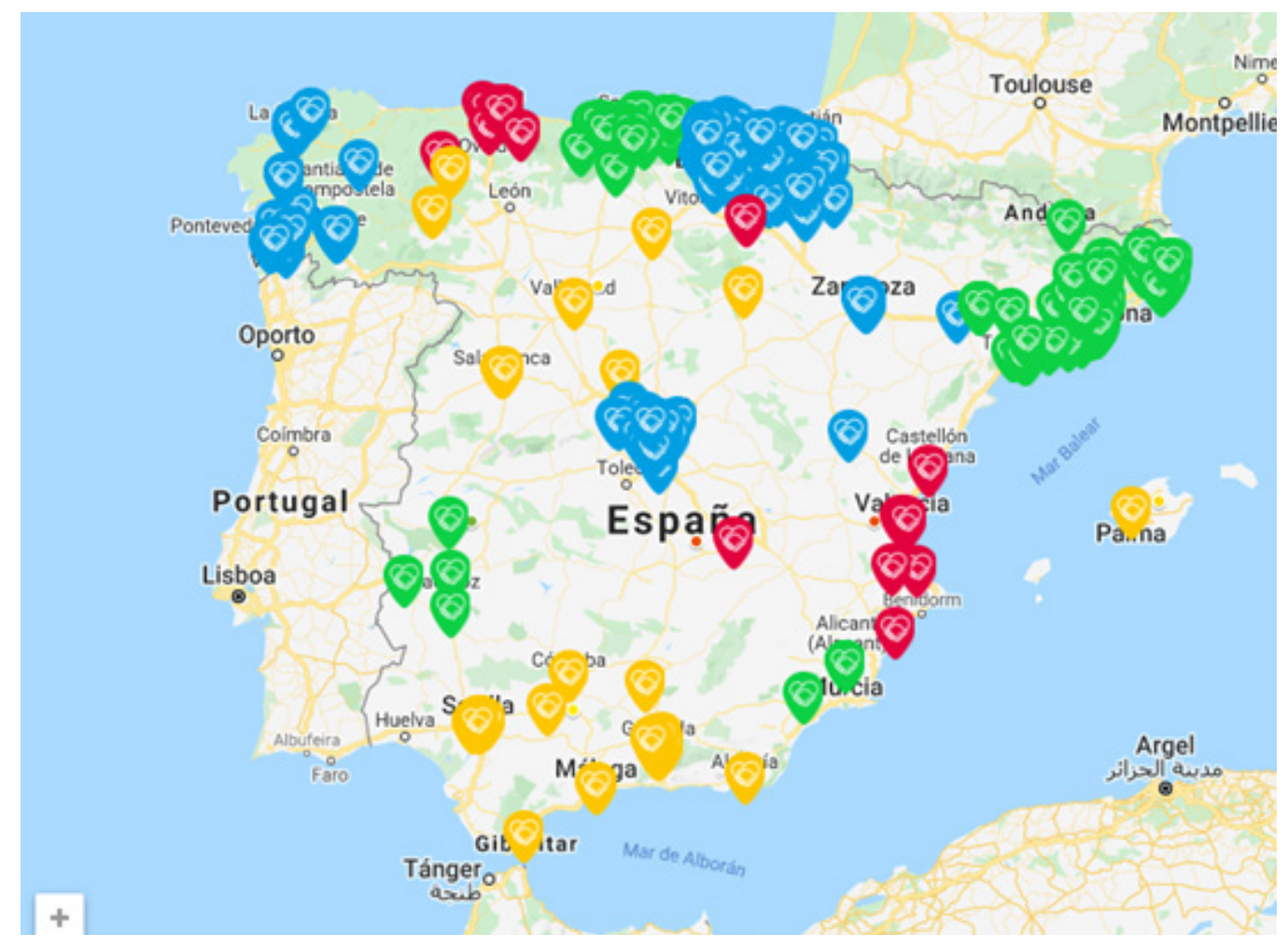

Imagen 4: Mapa de las redes de apoyo mutuo y solidaridad que se formaron en España durante los primeros meses tras el primer estado de alarma. Fuente: https://www.google.com/maps/ $\mathrm{d} / \mathrm{u} / 0 /$ viewer? $\mathrm{mid}=1 \mathrm{Am} 4$ eiN8rkZTglowce6GSVqsJvYEdOWTL\&ll=39.58857290783863\%2C$1.6440627246301887 \& \mathrm{z}=6$

Asimismo, para este escrito resulta importante mencionar que, además de las acciones organizadas en grupos y colectivos, como las atrás mencionadas, se articularon otras

16. El diario El Periódico realizó un reportaje que se puede consultar en el siguiente enlace: https://www. elperiodico.com/es/barcelona/20200801/la-marca-top-manta-se-vuelca-en-las-mascarillas-8048724 
prácticas más minúsculas, microscópicas, que no toman una forma concreta pero que resultan altamente significativas para la vida diaria. Así, durante los momentos más duros del confinamiento y la expansión del coronavirus, la cotidianidad alterada de las personas migrantes se transfiguró en diferentes formas de apoyo, cuidado, solidaridad y empatía. Por ejemplo, algunas de las personas que respondieron nuestro cuestionario realizaron acciones en favor de amigos, familiares y conocidos haciendo uso de plataformas electrónicas para comunicarse entre sí. Recordemos que la movilidad estaba restringida, así como realizar talleres, charlas y actividades lúdicas. Una de nuestras entrevistadas lo comenta así:

"Los grupos de colegas (estudio) o amigos con intereses afines fueron significativos con su contacto para lidiar con las consecuencias psicológicas derivadas del aislamiento y la ansiedad frente a la amenaza de contagio o enfermedad".

También consideran que estas "prácticas minúsculas" "tienen un impacto grande, porque el apoyo fue muy rápido y directo”. Pero, además, no solo se trataba de actuar a favor de los demás, sino también en "aceptar ayuda de los más cercanos para soportar el encierro"; son acciones de reciprocidad espontánea que permiten atenuar la crisis sanitaria y evitar mayores daños entre las personas vulnerables.

En general, las personas que respondieron a nuestro cuestionario ocupaban de dos o tres días a la semana para realizar las actividades individuales y colectivas, si bien algunos dedicaban un tiempo todos los días. De modo que su vida cotidiana no quedó paralizada frente a la amenaza provocada por el covid-19, sino que se articuló en formas comunitarias para enfrentar la pandemia.

\section{CONCLUSIONES}

Este trabajo es una perspectiva - en términos de Nietzsche - de aproximación a una serie de problemas sociales que hemos delimitado desde un principio: ¿cuáles son algunas "prácticas cotidianas" de los migrantes en Barcelona frente al covid-19?, ¿cuáles son algunas de las organizaciones que realizaron acciones de ayuda?, ¿qué papel jugó el Estado en estos procesos? Es una propuesta que no pretende ser exhaustiva, ni definitiva, y que más que dar respuestas últimas o concluyentes a las preguntas planteadas, pretende incitar a la reflexión sobre estas cuestiones, pues plantear las preguntas adecuadas puede ser heurísticamente más provechoso que responderlas. Además, ninguna respuesta es definitiva y no existe una Verdad última de los procesos sociales e históricos ni del anthropos.

Desde el principio hemos dejado explicitadas claramente nuestras bases teóricas y metodológicas, por lo que este estudio no pretende ser neutral en absoluto; seguramente existen muchos "pre-juicios" (Gadamer, 1977) inconscientes que responden a intereses propios de quien escribe estas líneas. Igual que sucede con cualquier investigación en 
ciencias sociales y humanidades, pero también en las llamadas "ciencias de la naturaleza" (Dilthey, 1980).

Dicho lo anterior, proponemos comprender que los migrantes que viven en Barcelona encarnan unas tradiciones, culturas, creencias, hábitos, lenguajes, idiomas, experiencias, que se pueden comprender en su vida cotidiana como unas "costumbres" que son al mismo tiempo una ética y una estética que se despliegan en el conjunto de la ciudad por medio de los usos, significaciones y praxis que realizan diariamente y que proliferan y se esparcen entre las grietas de la sociedad dominante con un impacto directo en la vida urbana. En el contexto en el que nos encontramos, con el covid-19, las "prácticas migrantes" de cuidado alimentario, apoyo emocional, asistencia sanitaria, asesorías jurídicas, donación de dinero, entrega de ayudas materiales de todo tipo, etcétera, no solo adquieren una forma concreta a través de sus organizaciones y colectivos, como la Red de Cuidados, sino también en sus praxis más íntimas, aparentemente alejadas de la "política", se configura una socialidad microscópica que también pertenece a la vida de la ciudad.

La España dominante de las instituciones del Gobierno, el Congreso, sus policías y algunas empresas niegan la "regularización" de las personas "sin papeles", sobreexplotan a los trabajadores hasta el punto de la muerte, realizan "redadas racistas", impiden y obstaculizan las labores humanitarias de organizaciones sociales, como la Red de Cuidados Antirracista, creando un ambiente sociopolítico de hostilidad, discriminación y racismo.

Observamos en la ciudad de Barcelona dos grandes lógicas (hay más por supuesto) de enfrentar los problemas sociales producidos y agudizados por la pandemia actual, que son parte de un mismo proceso histórico, político y social que está transformado el conjunto de las relaciones entre instituciones y sociedad, capital y trabajo, vida cotidiana y política. Proponemos como hipótesis general que en este contexto de crisis global y total se hace más clara la posibilidad de que la concepción misma del anthropos, "la imagen del ser humano" (Rombach, 2004), sufra unas modificaciones hermenéuticas y experienciales impulsadas por los sectores más vulnerables, aquellos en riesgo de exclusión social, que son menospreciados por el orden dominante, pues ahí, entre las líneas de la "marginalidad" se entretejen y configuran formas de socialidad alternas al capitalismo hegemónico y, por lo tanto, “imágenes” nuevas y alternas del mundo y del ser humano.

En este sentido las "prácticas cotidianas" de las personas migrantes, que hemos estudiado aquí, no son simplemente una "respuesta" directa a la amenaza del covid-19, sino también son una muestra germinal de otras formas de socialidad, de relaciones económicas opuestas al "valor de cambio", de modos de comportamiento alternos, de establecimiento de nuevas jerarquías para los "valores". Constituyen prácticas que no 
se corresponden con las de la sociedad hegemónica y que incluso entran en choque con la lógica dominante de las instituciones estatales. Alteran el curso lineal de la historia, de la política y de la ciudad. Son el "retorno de lo reprimido" por los siglos de colonización, esclavismo y racismo.

Al mismo tiempo es importante constatar que las "prácticas culturales" (Cassigoli, 2005) de las personas migrantes en Barcelona, como la Red de Cuidados aquí analizada, consiguieron salvar decenas de vidas humanas, evitar una mayor propagación del coronavirus, disminuir hambres y otras enfermedades en los inmigrantes más vulnerables en España: madres solteras, trabajadoras sexuales, recolectores de chatarra, vendedores ambulantes, enfermos, adultos mayores, personas sin casa, desempleados.

Destacamos que en estas "prácticas" la ciudad es el escenario del "teatro", en el que la vida cotidiana de los migrantes toma forma y da forma a la misma urbe a través de los usos y significaciones que se hacen de los espacios autogestionados como son: librerías, ateneos, tiendas, comedores populares, calles, plazas, etc. En este ámbito, también consideramos importantes las "narrativas" de la ciudad: cómo los migrantes la describen en sus comunicados y mensajes, en la elaboración de mapas de las rutas de cuidado, en las fotos que publican en sus redes sociales. Todas estas praxis también "producen" (Lefebvre, 1973) la ciudad.

Barcelona no solo está constituida por sus barrios, edificios, mercados, plazas, calles, comercios, banca y gobierno, "la ciudad material", también se compone de los deseos, los sueños, los anhelos, los miedos, los fantasmas, las sombras, de todos sus habitantes que han vivido en ella por generaciones. La ciudad es también una "estructura de acogida" (Duch, 2002) de la vida cotidiana, una "realidad simbólica", en la que, para bien y para mal, se despliegan y se entrecruzan las lógicas sociales más diversas y antagónicas que entran en conflicto y van dando forma a la historia social de la ciudad. Los migrantes juegan un papel en todos estos procesos desde hace generaciones y hoy en día siguen practicando sus propias formas de vivir y crear la ciudad.

La pandemia provocada por el covid-19 seguramente ha sacado lo "peor" y lo "mejor" del ser humano en todos los rincones del mundo. En este trabajo, lo que podemos constatar en lo que se refiere a la vida cotidiana de los migrantes que viven en Barcelona es una "politización del habitar" la ciudad que se expresa en formas de solidaridad, apoyo mutuo, empatía y que muestra que es posible seguir construyendo alternativas sociales a las tendencias dominantes actuales. Es en la vida cotidiana donde se configuran los procesos sociales, donde se vive dramáticamente la historia y se realiza la "construcción social de la realidad" (Berger y Luckmann, 2003). 


\section{REFERENCIAS BIBLIOGRÁFICAS}

Aristóteles (2015) Política. Madrid: Alianza Editorial.

Berger, Peter y Thomas Luckmann (2003) La construcción social de la realidad. Buenos Aires: Amorrortu Editores.

Cassigoli, Rossana (2016) “Antropología de las prácticas cotidianas: Michel De Certeau”. Chungara, Revista de Antropología Chilena, 48(4): 679-689.

(2005) "Prácticas culturales y politización de la pertenencia”. Revista LIDER, 14: 21-40.

De Certeau, Michel (1996) La invención de lo cotidiano I. Artes de hacer. México: Universidad Iberoamericana.

Dilthey, Wilhem(1980)Introducciónalascienciasdelespíritu:ensayodeunafundamentación del estudio de la sociedad y de la historia. Madrid: Alianza.

Duch, Lluís (2015) Antropología de la Ciudad. Barcelona: Herder.

(2002) Antropología de la vida cotidiana, Simbolismo y salud, tomo I. Madrid: Editorial Trotta.

(2000) Llums i sombres de la ciutat. Antropologia de la vida quotidiana 3. Montserrat: Publicacions de la Abadia de Montserrat.

Gadamer, Hans Georg (1977) Verdad y método: Fundamentos de una hermenéutica Filosófica. Salamanca: Sígueme.

Gálvez, Ismael (2020) The size, socio-economic composition and fiscal implications of the irregular immigration in Spain, [en línea]. Madrid: Universidad Carlos III. D, disponible en: https://e-archivo.uc3m.es/handle/10016/30643 [Consultado el 26 de octubre de 2020].

Harvey, David (2013) Ciudades rebeldes. Del derecho a la ciudad a la revolución Urbana. Madrid: Akal.

Lefebvre, Henri (1947) Critique de la vie quotidienne. París: Editions Bernard Grasset. (1973) El derecho a la ciudad. Barcelona: Editorial Península.

(2013) La producción del espacio. Madrid: Capitán Swing.

Márquez, Ulises (2020) “Guía de observación para explorar las 'prácticas cotidianas' de las personas migrantes ante el COVID-19 en Barcelona”. Disponible en: https://forms. gle/yUnaNW7w1znc2nL58 [Consultado el 26 de octubre de 2020].

(2017) "El estudio de la vida cotidiana a través de tres perspectivas teóricas: del materialismo histórico de Henri Lefebvre y Agnes Heller a la antropología simbólica de Lluís Duch". Tesis de doctorado, Universidad Nacional Autónoma de México. 
Messias, Naty (2020) "Entrevista con TV3 (1 de abril)". Disponible en: https://www. facebook.com/watch/?ref=saved\&v=269415417412933 [Consultado el 26 de octubre de 2020].

Nietzsche, Friedrich (2015) La voluntad de poder. Madrid: Edaf.

Ortiz, Renato (2004) Mundialización y cultura. Colombia: Edición del Convenio Andrés Bello.

Real Decreto 463/2020 (2020, 14 de marzo). Madrid: Ministerio de Sanidad, Consumo y Bienestar Social, Gobierno de España. Disponible en: https://spass.es/es/rd-463/2020de-14-de-marzo-por-el-que-se-declara-el-estado-de-alarma-para-la-gestion-de-lasituacion-de-crisis-sanitaria-ocasionada-por-el-covid-19.html [Consultado el 26 de octubre de 2020].

Real Decreto-ley 13/2020 (2020, 7 de abril). Madrid: Ministerio de la Presidencia, relaciones con las cortes y memoria democrática, Gobierno de España. Disponible en: https://www.boe.es/buscar/pdf/2020/BOE-A-2020-4332-consolidado.pdf [Consultado el 26 de octubre de 2020].

Red de Cuidados Antirracista (2020). "Comunicado por las multas contra integrantes de la Red de Cuidados Antirracista" (12 de abril). Disponible en: https://www.facebook. com/redcuidadosbarcelona/posts/123380962641450 [Consultado el 26 de octubre de 2020].

(2020) "Tres meses de actividad" (15 de junio). Disponible en: https://www. facebook.com/redcuidadosbarcelona/posts/151157466530466 [Consultado el 26 de octubre de 2020].

(2020) "Solidaridad y dignidad, procesos comunitarios de sostén de la vida" (18 de marzo). Disponible en: https://www.facebook.com/redcuidadosbarcelona/ posts/115462883433258 [Consultado el 26 de octubre de 2020].

(2020) "Solidaridad y dignidad" (30 de marzo). Disponible en: https://www. facebook.com/redcuidadosbarcelona/photos/este-martes-31-de-marzo-seguimos-conel-acompa\%C3\%B1amiento-y-apoyo-mutuo-de-compa\%C3\%B1er/115457483433798/ [Consultado el 26 de octubre de 2020].

(2020) "Comunicado en relación a la aprobación del real decreto-ley 13/2020, de 7 de abril". Disponible en: https://www.facebook.com/redcuidadosbarcelona/ posts/121661719480041 [Consultado el 26 de octubre de 2020].

Rombach, Heinrich (2004). El hombre humanizado. Antropología estructural. Barcelona: Herder.Sassen, Saskia (1999) La Ciudad Global, Nueva York, Londres, Tokio. Argentina: Eudeba. 
SOS Racisme (2020) "El racisme institucional castiga i criminalitza els temporers de Lleida amb controls policials" (23 de junio). Disponible en: http://www.sosracisme. org/wp-content/uploads/2020/06/ComunicatBatudesLleida.pdf [Consultado el 26 de octubre de 2020]. 